\title{
Primary Prostate Urothelial Carcinoma
}

National Cancer Institute

\section{Source}

National Cancer Institute. Primary Prostate Urothelial Carcinoma. NCI Thesaurus. Code C39898.

An urothelial carcinoma that arises from the urothelial lining of the prostatic ducts or the prostatic urethra. 